\title{
Proyecciones audiovisuales LGBTQIAP +: arte y activismo en los ambientes externos
}

\author{
LGBTQIAP + audiovisual projections: art and activism in the external
}

environment

\begin{abstract}
Daniel Jesús de Souza PRAZERES. Universidade Anhembi Morumbi (Brasil). dprazeres@danielprazeres.com.br

Suzete VENTURELLI. Universidade Anhembi Morumbi (Brasil). suzeteventurelli@ gmail.com
\end{abstract}

\begin{abstract}
Resumen: Este artículo busca reflexionar sobre las proyecciones audiovisuales en el arte activista que abordan la temática LGBTQIAP + realizadas en el espacio urbano, destacando con más atención para el trabajo de los artistas y sus expresiones en el período pandémico de 2020. Dudas, miedos, apatía, miedo, empatía, revueltas, solidaridad, afirmaciones, negaciones, mentiras y verdades, son algunos de los sentimientos que provocaron reacciones en la población brasileña, desde los más diversos ámbitos sociales. Para esto, el texto tiene principio la revisión bibliográfica de ciertos temas específicos en torno al concepto proyección, lo que incluye analizar las publicaciones virtuales que documentan las intervenciones realizadas en la ciudad. Se percibe una articulación por parte de algunos grupos sociales y políticos en el fortalecimiento de la conciencia política que abraza el activismo LGBTQIAP+, en la lucha del fortalecimiento de la identidad de género y de los derechos que los líderes políticos insisten en sustraer o disminuir de estos grupos. Finalmente, considera que la intervención provocada por las imágenes proyectadas sobre las arquitecturas fortalece la conciencia política que justamente considerase el puro activismo. Así, le corresponde al observador, a partir de su experiencia cotidiana, buscar el significado de las superposiciones resultantes entre las camadas de las imágenes proyectadas en la ciudad.
\end{abstract}

Palabras clave: Diseño, Arte, Activismo, LGBTQIAP +, Proyección Audiovisual, Espacio urbano. 


\begin{abstract}
This article seeks to reflect on the audiovisual projects in activist art that address the theme LGBTQIAP + carried out in the urban space, highlighting the greater attention to the work of artists and their expressions in the pandemic period of 2020. Doubts, fears, apathy, fear, empathy, revolts, solidarity, affirmations, denial, lies and truths, are some of the feelings that provoked reactions in the Brazilian population, from the most diverse social spheres. To this end, the text begins with a bibliographic review of some specific topics around the design of the project, which includes the analysis of virtual publications that document the interventions performed in the city. An articulation on the part of some social and political groups is perceived in strengthening the political conscience, in the search of the strengthening of the gender identity and of the rights that political leaders insist in subtracting or diminishing. Finally, he considers that the intervention provoked by the images projected on the architectures strengthens the political conscience that is rightly considered pure activism.
\end{abstract}

Keyword: Design, Art, Activism, LGBTQIAP +, Audiovisual Projection, Urban space

\title{
Introducción
}

Este artículo presenta una reflexión sobre las convergencias entre prácticas artísticas y activismo contemporáneo, a través de proyecciones audiovisuales realizadas en 2020 desde diferentes contextos. Investiga los conceptos y objetivos con compromiso social, considerando la temática LGBTQIAP $+{ }^{1}$, y sus formas de la experimentación estética, la expresión política y su subjetividad contemporánea.

Para entender estas acciones, es necesario esclarecer el momento histórico en el que permean las intervenciones en las ciudades brasileñas, en un escenario que refleja un tipo de actitud hacia el nuevo Coronavirus (COVID-19) ${ }^{2}$, dudas, miedos, apatía, miedo, empatía, revueltas, solidaridad, afirmaciones, negaciones, mentiras y verdades, son algunos de los sentimientos que provocaron reacciones en la población brasileña, desde los más diversos ámbitos sociales.

China fue considerada el epicentro de la epidemia que pronto se apoderó de los continentes. Pero, en mayo de 2020, Brasil asume este triste escenario, dadas las tasas de contagio y muerte que crecen continuamente, según Barrucho, (2020), "El gobierno brasileño ha perdido el control de la pandemia. (...) Puedo afirmar categóricamente que Brasil se ha convertido en el polo más importante de propagación del virus covid-19 en el mundo".

1 LGBTQIAP + es un acrónimo que engloba a las personas que son lesbianas, gays, bisexuales, transexuales, queer / cuestionadores, intersexuales, asexuales / arrománticos / género, pan / polisexuales y más. Disponible en: <https://orientando.org/o-que-significa-lgbtqiap/>. Consultado el 22 de junio. 2020.

2 El nuevo agente de coronavirus (Covid-19) fue descubierto el 31/12/19 después de que se registraran casos en China. Disponible en: <https://coronavirus.saude.gov.br/sobre-a-doenca>. Consultado en: 16 de junio. 2020. 
La Organización Mundial de la Salud - $\mathrm{OMS}^{3}$, presentó acciones y procedimientos de salud, todavía, cada representante y administrador político ha planeado los procedimientos según sus intereses políticos, económicos y de salud para contener el virus. En este contexto, el aislamiento social ${ }^{4}$, fue uno de los recursos utilizados para reducir el contagio, y ante esta opción, se desalentaron las manifestaciones políticas presenciales y las aglomeraciones sociales o culturales.

La proyección audiovisual presenta una reflexión sobre las intersecciones entre la actividad artística y el activismo contemporáneo, que ansía cambios sociales y políticos, especialmente en el año 2020, que desde el aislamiento social consideró modos de experimentación estética y atribuyó conceptos y objetivos de un arte socialmente comprometido. A partir de esta situación, las manifestaciones LGBTQIAP+, a través de estas intervenciones artísticas, repercutieron en las redes sociales, cuestionando y fortaleciendo su identidad y su posición política y social.

\section{La oscuridad no impedirá que el arcoíris brille}

El escenario pandémico contribuyó a acentuar la proyección audiovisual como la voz de artistas y colectivos, que buscaban abordar temas de actualidad y cuestiones de intervención en el espacio exterior de las ciudades. Estos movimientos sociales también pueden definirse como una articulación basada en un conjunto de intereses y valores comunes, ya que tienen como objetivo cambiar el orden social existente, provocar interrogantes e incidir en los resultados de procesos sociales y políticos que involucran valores o comportamientos sociales (Machado, 2007).

En este sentido, el colectivo \#Projetemos ${ }^{5}$, surgió ante la apatía de los individuos en relación al virus COVID-19, a los hechos y a las ideologías impuestas por el poder público. En este contexto, optaron por la proyección audiovisual, como medio de expresión para reforzar la importancia del aislamiento social, en una especie de guerrilla en la que los medios digitales son las armas de defensa y ataque para el emisor del mensaje que se genera.

3 Organización Mundial de la Salud - OMS, presentó la propuesta para ocuparse de los problemas relacionados con la salud global. Su propuesta es ayudar a los gobiernos en el fortalecimiento de los servicios de salud y erradicación de enfermedades, actuando sobre nutrición, vivienda, saneamiento, recreación, condiciones económicas y laborales. Proporciona información sobre la salud y la clasificación internacional de enfermedades. Disponible en: <https://saude.estadao.com.br/noticias/geral,brasil-teve-papel-direto-na-fundacao-da-omsentenda-o-que-eea-funcao-da-organizacao, 70003256316>. Consultado en: 18 de junio. 2020.

4 El 12 de marzo de 2020, el Ministerio de Salud publicó la Ordenanza No. 356/3020, que regula las medidas para atender la emergencia de salud pública de importancia internacional por el coronavirus (Covid-9). La medida regula la Ley 13.979 / 20. Disponible en: <https:/www.gov.br/pt-br/noticias/ saude-e-vigilancia-sanitaria/2020/03/ministerio-da-saude-regulamenta-medidas-de-isolamento-equarentena $>$. Consultado en: 16 de junio. 2020.

5 En una entrevista, Mozart aclaró el inicio del colectivo, que tenía como objetivo la sensibilización y el esclarecimiento político y la epidemia de COVID-19. Disponible en <https://artebrasileiros. com.br/arte/cidade/projetemos-isolamento-social-coronavirus/>. Consultado el 23 de mayo de 2020. 


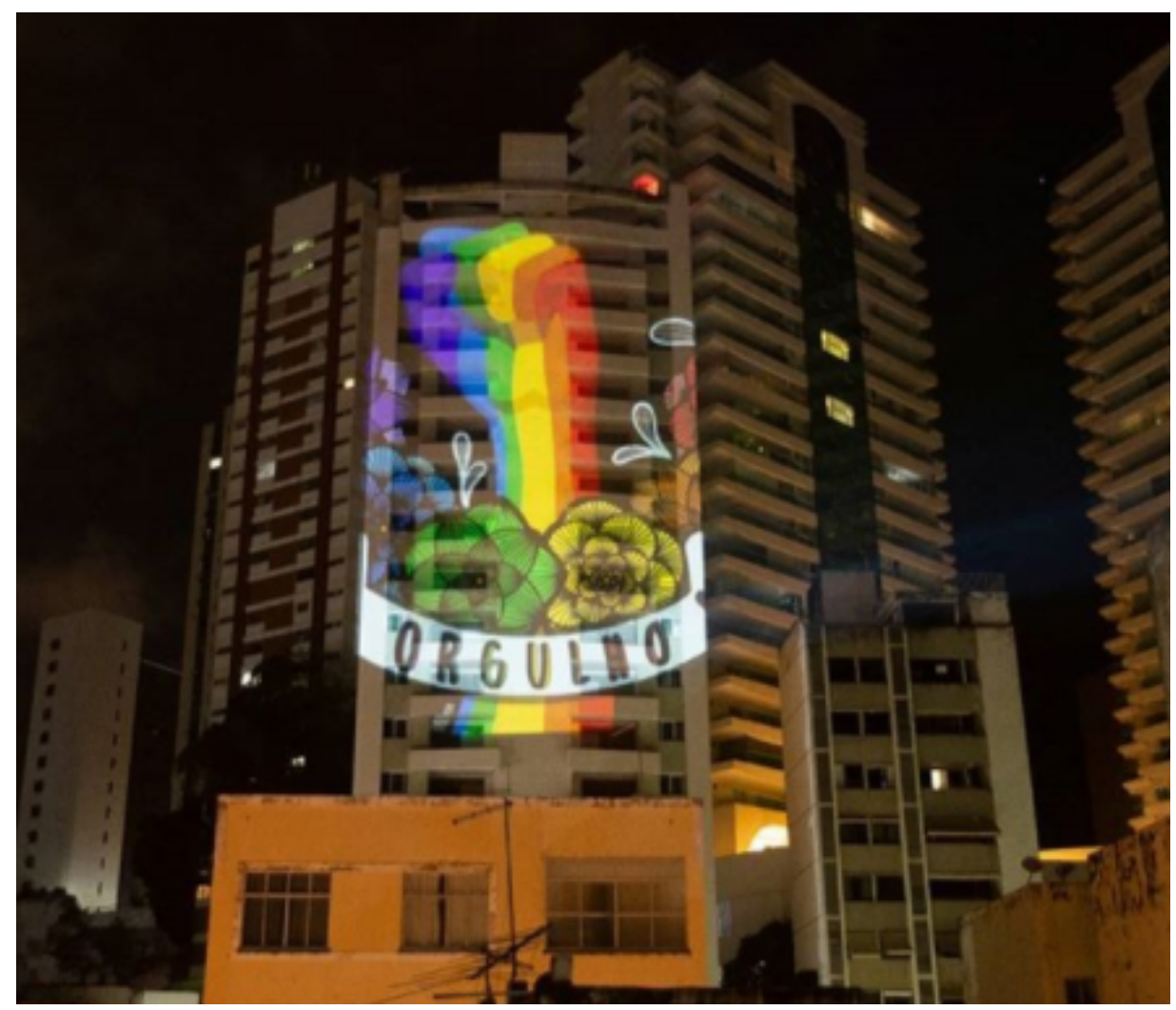

Figura 1. Orgullo - @projetemos (2020)

Fuente: Disponible en: <https://www.instagram.com/p/CCAwG00HqIk/?utm_source=ig_web_button_share_ sheet>. Consultado el 16 de noviembre. 2020.

Este movimiento lleva la solidaridad y la transgresión, lo colectivo y la acción, que caracterizan el tipo de activismo propuesto. Las transgresiones cuestionan las normas sociales, con respecto a las creencias, las desigualdades y las opresiones (Mesquita, 2008, en Jordan, 2002, p.12).

De esta manera, permiten que la voz de la rebelión se perpetúe en el escenario urbano y pandémico, ya que los medios digitales tienen un rol importante a cumplir como vehículo, permitiéndoles llegar a las personas en sus ciudades. Las tecnologías de acción remota agregadas a las redes sociales se han vuelto participativas y preponderantes para tomar posición sobre cualquier tema. Sevcenko (2001, p. 17), dice que, "la crítica, por tanto, es la contraparte cultural de la técnica, es la forma en que la sociedad dialoga con las innovaciones, ponderando su impacto, evaluando sus efectos y analizando sus desarrollos". En este contexto, Mesquita (2008) y Hora (2019) corroboran el entendimiento de que la experiencia de interacción con la materialidad de las cosas con las redes de comunicación vía internet y el acceso a las nuevas tecnologías permitió que diferentes grupos se organizaran de acuerdo con sus necesidades. 
São Paulo es considerada la ciudad con el Desfile Gay más grande del mundo, y el país Brasil, por tener el mayor número de ciudades que se han sumado a esta manifestación. Se convirtió en la ruta del turismo gay, y el movimiento activista se convirtió en un referente mundial, ubicándolo entre las ciudades más gay del mundo (Trindade, 2011).

Pero este aporte económico no impidió el pensamiento retrógrado del gobierno de Bolsonaro ${ }^{6}$, en la comprensión de la igualdad de género y los derechos LGBTQIAP+ ${ }^{7}$, cuya visión estereotipada de cuestiones ideológicas religiosas y de género permean los discursos políticos en un intento de disfrazar el odio y la homofobia, por parte de los parlamentarios y representantes de partidos del gobierno.

Hubo innumerables boicots en actividades con temas LGBTQIAP+, como la suspensión de la financiación de películas y eventos culturales, y la presentación de discursos que desacreditan los derechos ganados con tanto esfuerzo de la comunidad. Hubo incrementos significativos, pero estas acciones solo fueron posibles, dado el movimiento social y los parlamentarios simpatizantes de la causa. En este contexto, se logró aprobar la ley que tipifica la homofobia y transfobia como delitos de racismo ${ }^{8}$, contribuyendo a la libertad y la manifestación de la identidad de género, y al fortalecimiento de la seguridad a través del acompañamiento legal.

La pandemia cambió las actividades del Día Internacional del Orgullo LGBTQIAP+, las concurridas calles, bares, restaurantes, centros comerciales, hoteles, eventos y discotecas después de las fiestas, fueron canceladas independientemente de los géneros o empresas que se benefician. económicamente para este entretenimiento activista.

Para comprender la relevancia de la proyección en la Figura 2 es necesario contextualizar la importancia de esta intervención, en el año 2019, pues en el congreso se hizo eco de la icónica frase de posesión de la Ministra Pastora Damares Alves, que representa el Ministerio de Mujer, Familia y Derechos Humanos, quien declaró que "Es una nueva era en Brasil: el niño viste de azul y la niña de rosa".

6 Jair Bolsonaro, fue elegido en octubre de 2018 con el 55,13\% del electorado. Disponible en: <https://www. gov.br/planalto/pt-br/conheca-a-presidencia/biografia-do-presidente>. Acceso: 13 de diciembre. 2020.

7 Jaqueline Gomes de Jesus, es profesora de la IFRJ (Instituto Federal de Rio de Janeiro) y psicóloga, con un doctorado en Psicología Social del Trabajo de la UnB (Universidad de Brasilia) y un postdoctorado de la Facultad de Ciencias Sociales, de la Fundación Getúlio Vargas, aclara asuntos de la comunidad LGBTQI + con la llegada de la extrema derecha. Los reveses de la población LGBT + en 2019. Disponible en: <https://ponte. org/os-retrocessos-do-governo-bolsonaro-para-lgbt-em-2019/>. Acceso: 13 de diciembre. 2020.

8 El 13 de junio de 2019 se aprobó que las conductas homofóbicas y transfóbicas, reales o presuntas, se encuentran dentro de los delitos previstos en la Ley 7.716 / 2018. Disponible en: <http://www.stf.jus.br/portal/ cms/verNoticiaDetalhe.asp?idConteudo=414010>. Acceso: 13 de diciembre. 2020.

9 El 2 de enero de 2019, en posesión del portafolio de Mujer, Familia y Derechos Humanos, la ministra Damares Alves dio testimonio estereotipado de géneros a través de los colores de la ropa. Disponible en: $<$ https://oglobo. globo.com/sociedade/menino-veste-azul-menina-veste-rosa-diz-damares-alves-em-video-23343024>. Acceso: 13 de diciembre. 2020. 


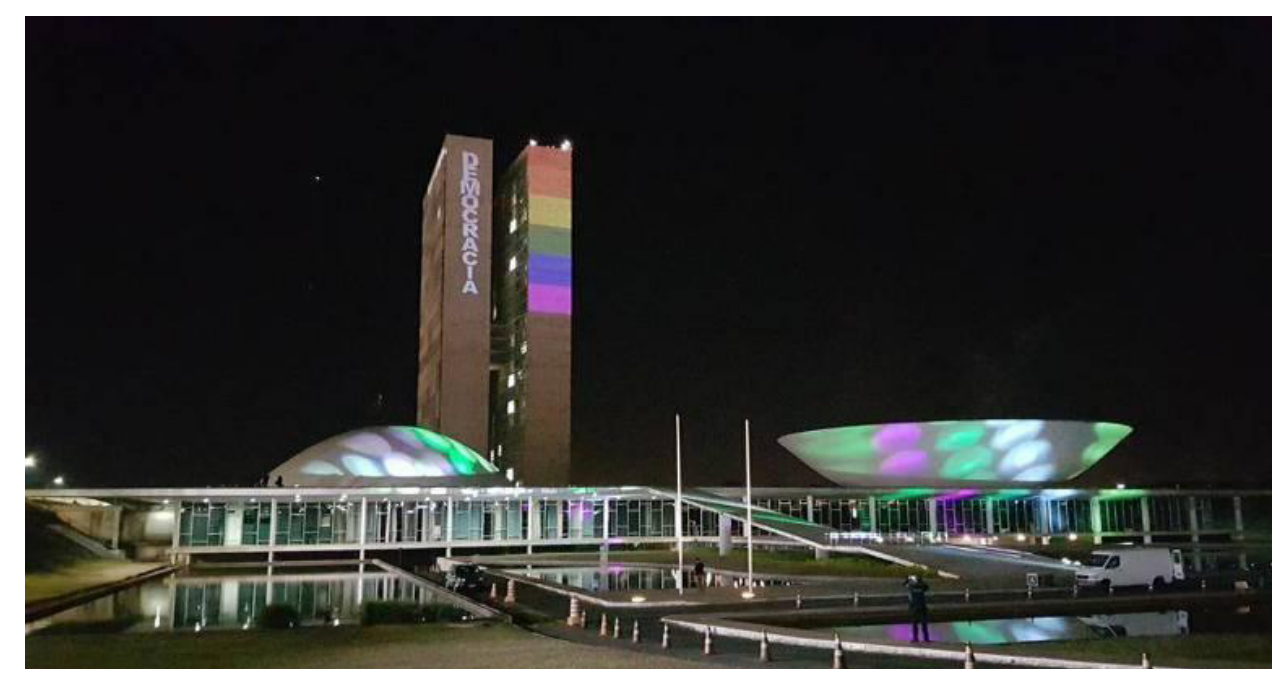

Figura 2. El Congreso recibe la proyección del arco iris por primera vez en el Día del Orgullo LGBT

Fuente: Disponible en: <https://www.uol.com.br/universa/noticias/redacao/2020/06/28/no-dia-do-orgulholgbtq-congresso-e-iluminado-com-as-colores-arcoiris.htm>. Consultado el 22 de diciembre. 2020.

Este discurso representó una ofensa a la propia constitución brasileña, que la Ministerio defiende, como se presenta en el artículo V de la fracción XIII ${ }^{10}$.

Como consecuencia, en el día dedicado al Día Internacional del Orgullo LGBTQI +, de una manera inédita, la arquitectura del Congreso Nacional se bañó de proyecciones activistas compuestas con los colores del arco iris y la palabra democracia, para reforzar que estamos en un estado democrático.

Esta acción recae en el sentido mismo de esta arquitectura modernista, que debe representar el predominio del poder del pueblo, cuyo lugar podría promover el diálogo y el derecho a la convivencia entre diferentes ideologías y corrientes, en la búsqueda de la tolerancia en torno a cuestiones religiosas y religiosas. género. Según Mesquita (2008), la esfera pública es como un campo de tensiones y diferenciaciones, ya que presenta en su formación fragmentaciones con múltiples formas de exclusión, contestación y conflicto. De esta manera, es un espacio fructífero de negociación, un espectáculo de contradicciones, con signos y simbologías inconstantes y siempre determinado por las relaciones sociales y políticas.

10 La Constitución Federal establece políticas y lineamientos para la promoción de los derechos humanos, incluidos los derechos de: a) las mujeres; b) la familia; c) el niño y el adolescente; d) juventud; e) ancianos; f) la persona discapacitada; g) la población negra; h) minorías étnicas y sociales; y combatir todas las formas de violencia, prejuicio, discriminación e intolerancia. Disponible en: $<$ http://www.planalto.gov.br/ccivil_03/_ ato2019-2022/2019/lei/L13844.htm>. Consultado en: 22 de diciembre. 2020. 


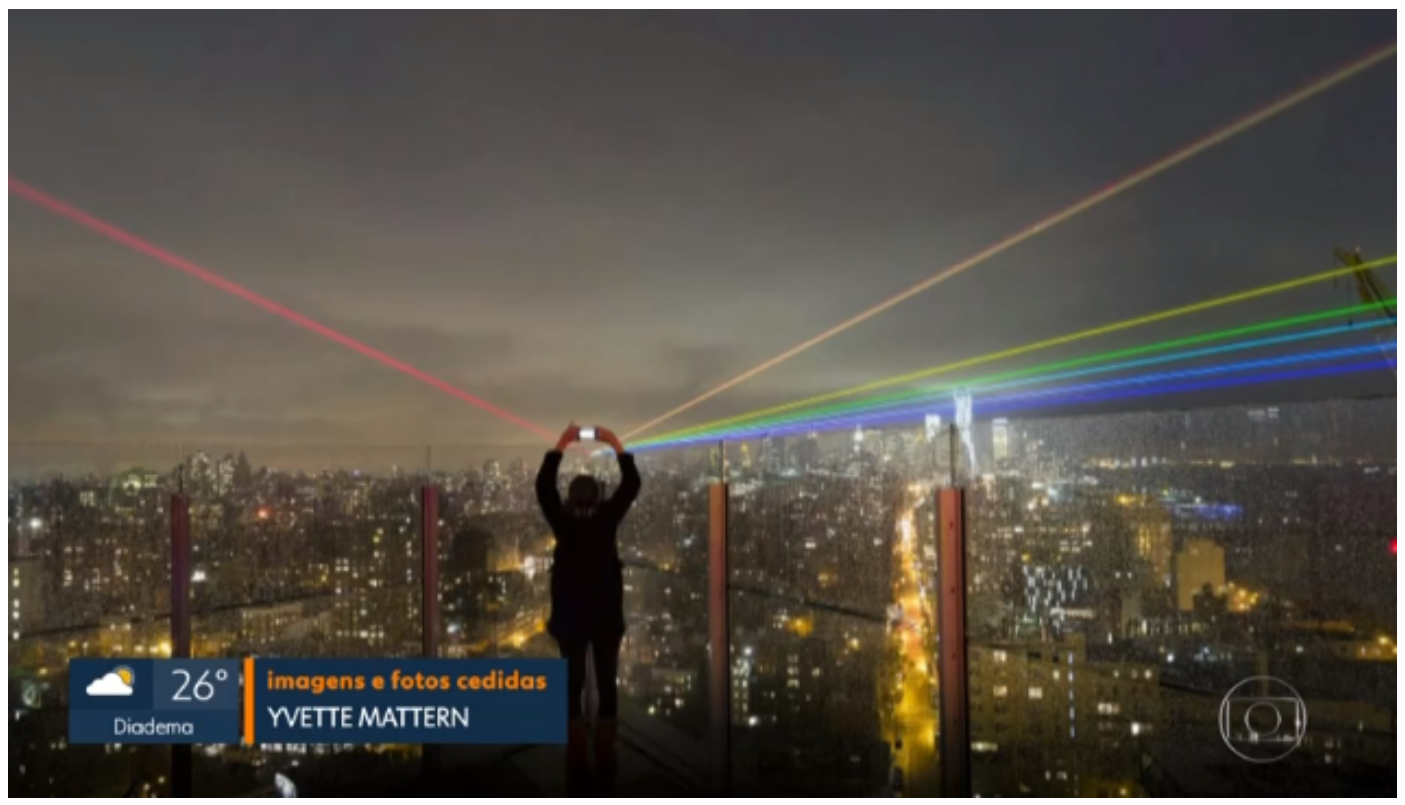

Figura $3.24^{\circ}$ Desfile LGBT en SP.

Fuente: Disponible en: <https://g1.globo.com/sp/sao-paulo/noticia/2020/06/13/parada-lgbt-de-sp-teraprogramacao-virtual-e-projecao-de- luces-en-av-paulista-este-domingo.ghtml>. Consultado el 21 de noviembre. 2020 .

Pero es necesario aclarar que según los artículos 4 IV y 5 VI de la Constitución Federal ${ }^{11}$, Brasil debe promover el bien de todos, sin perjuicio de origen, raza, sexo, color, edad y cualquier otra forma de discriminación y en el artículo $5^{\circ}$, VI, aclara el estado de ser secular.

El activismo político como proceso dinámico de intervención artística, y su inserción como militante, no se limita a experiencias previas, se renueva según las necesidades que surgen de la propia sociedad (figura 3). Sin las demostraciones cara a cara, el evento se llevó a cabo virtualmente y las luces del arco iris cortaron la oscuridad de la noche y las conferencias en línea abordaron temas contemporáneos de la población LGBTQI +. Así, esta intervención se refería a la forma, cómo cada individuo construye su forma de hacer y su forma de pensar en la vida cotidiana (Dell'Aglio, Almeida y Stenzel, 2013). Y a través de la reflexión, hay una transgresión de materialidades y retórica guiada por jerarquías preestablecidas, relacionadas con las artes visuales y el diseño, la arquitectura y el urbanismo (Hora, 2019).

São Paulo comparte esta inconstancia de signos y símbolos y las contradicciones sobre el derecho de la ciudad y del individuo, como podemos ver en la figura 4, del colectivo \#Projetemos. Este desafío y la desviación de funcionalidades que pretende la ciudad y la arquitectura, presenta alternativas poéticas, estéticas y críticas a través de intervenciones artísticas, que se basan en la tecnología y la redirección disruptiva de su propósito (Hora, 2019), que a través de proyecciones audiovisuales favorezcan a la comunidad LGBTQIAP+, para que se anulen las amenazas u opresión de los opositores a la causa.

11 La Constitución de la República Federativa de Brasil de 1988, diseñada para garantizar el ejercicio de los derechos sociales e individuales. Disponible en: < http:/www.planalto.gov.br/ccivil_03/constituicao/ constituicao.htm>. Consultado en: 16 dic. 2020. 


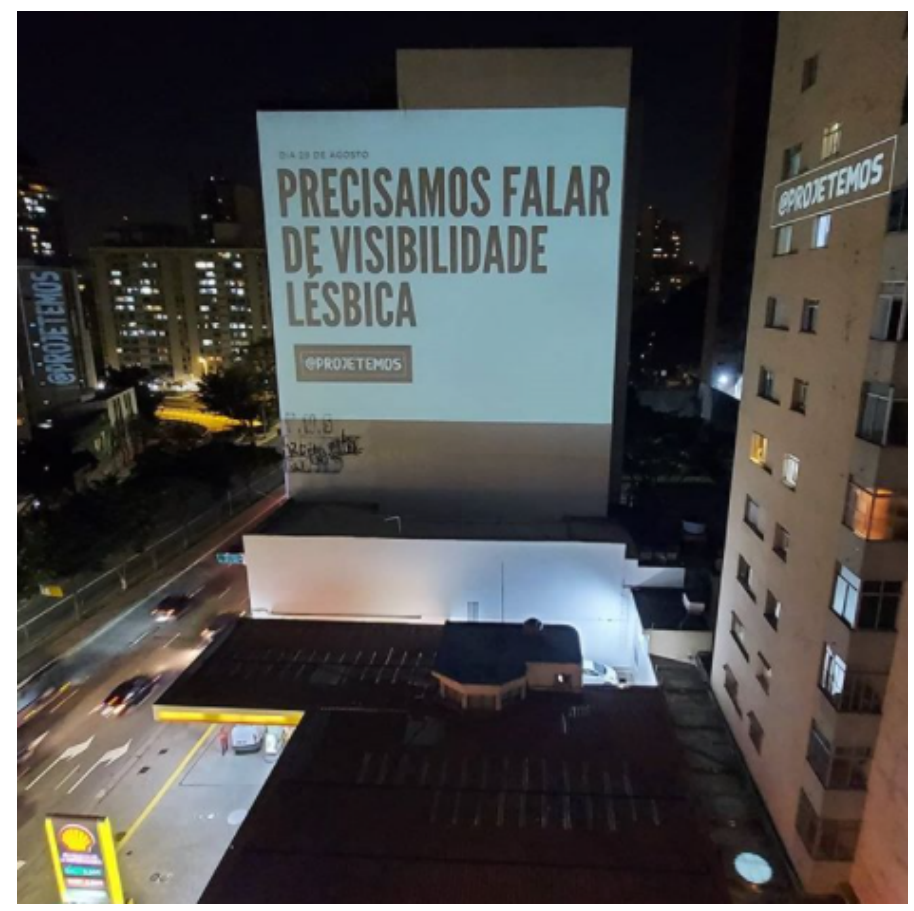

Figura 4. Necesitamos hablar de visibilidad lésbica - @projetemos (2020)

Fuente: Disponible en: <https://www.instagram.com/p/CEfhft7nBlS/?utm_source=ig_web_copy_link>. Consultado el 16 de noviembre. 2020.

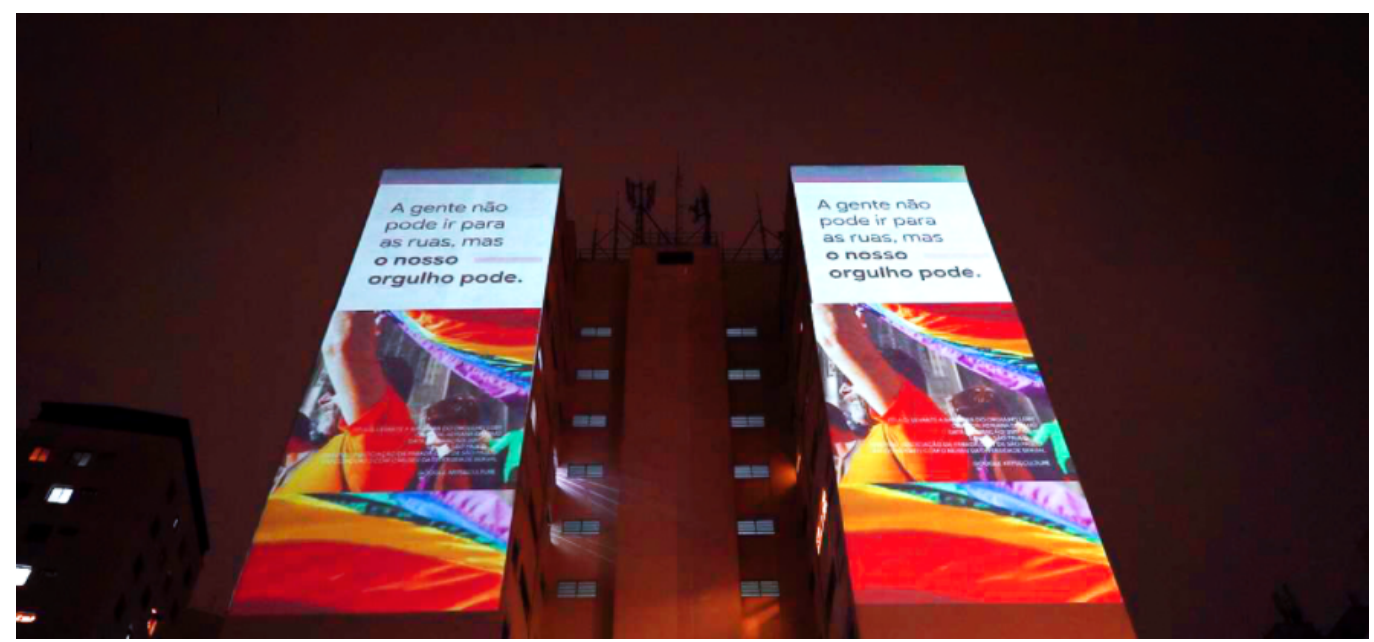

Figura 5. \#OrgulhodeSer - Manifiestos de Google para el mes del orgullo LGBTQ +

Fuente: Disponible en: <https://www.clubedecriacao.com.br/ultimas/orgulhodeser/>. Consultado el 21 de noviembre. 2020. 
A través de la alianza de la plataforma Google Arts \& Culture y el Museo de la Diversidad Sexual, se eligieron imágenes que forman parte de la exposición O Orgulho ocupa a Rua. La intervención del club creativo está compuesta por fotografías de ediciones del desfile del orgullo gay desde 1997 en São Paulo, esta acción es un potencializador y multiplicador de las estructuras de movilización del activismo (Dell’Aglio, Almeida y Stenzel, 2013).

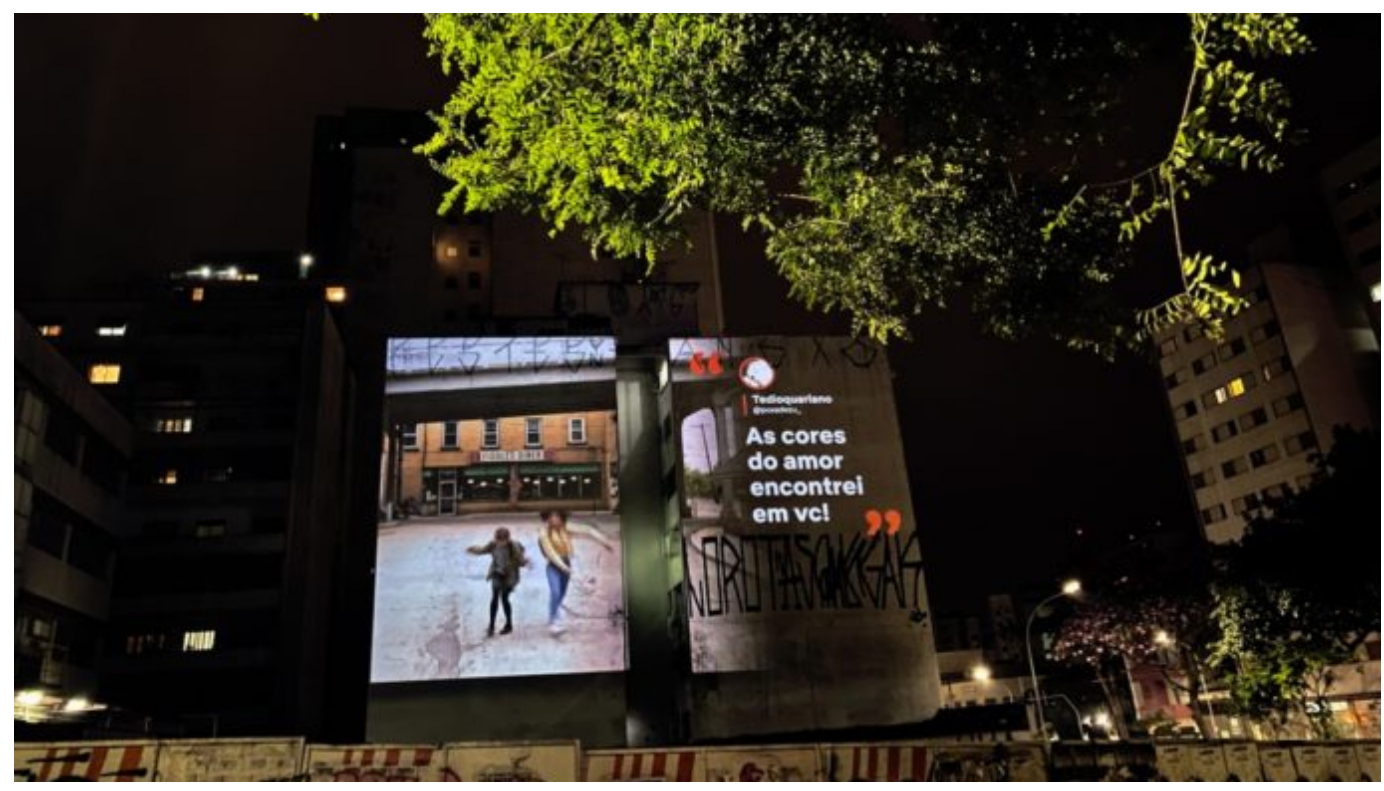

Figura 6. Netflix exhibirá personajes LGBT en las calles de SP el día del Desfile

Fuente: Disponible en: <https://observatoriog.bol.uol.com.br/noticias/netflix-exibira-personagens-lgbt-nasruas-de-sp-no-dia-da-parada>. Consultado el 21 de noviembre. 2020

Las acciones de intervención urbana con temática LGBTQIAP+, no provienen de artistas, activistas y colectivos, empresas de alta visibilidad e interés en este público, presenta acciones que contribuyen a una sociedad más inclusiva como lo presenta NETFLIX (Figura 6). La intervención proyectó escenas de películas que dialogan con la comunidad. En este sentido, no se trata solo de una acción para buscar formatos colaborativos o producir nuevas formas de sociabilidad, sino en la búsqueda incesante de ganar visibilidad en los medios y en el circuito del entretenimiento a través de un proyecto comercial (Mesquita, 2008, p.148), de alguna manera que, en la sociedad mercantil, el consumismo se propondría como la terapia para paliar el malestar que genera la propia esencia de este sistema, centrado en el mercado y no en los valores humanos (Sevcenko, 2001, p.88).

\section{Consideraciones finales}

El propósito de este artículo fue investigar cómo la intervención artística a través de proyecciones audiovisuales aborda los movimientos LGBTQIAP+y percibe la construcción del activismo, que se lleva a cabo en el espacio urbano. El escenario de la pandemia tuvo 
una adición considerable a los modos estándar y operativos atribuidos a las actividades del Día Internacional del Orgullo LGBTQIAP+.

Se percibe una articulación por parte de algunos grupos sociales y políticos en el fortalecimiento de la conciencia política que abraza el activismo LGBTQIAP+, en la lucha del fortalecimiento de la identidad de género y de los derechos que los líderes políticos insisten en sustraer o disminuir de estos grupos.

A partir de las preguntas y las proyecciones en el espacio urbano externo, es posible identificar la acción que fortalece las experiencias y su relación en una identidad política y sexual que contribuyen a la democracia superar un pensamiento separatista y opresivo. La crítica se lleva a cabo a través de la tecnología de proyección audiovisual para filtrarse por el paisaje, dialogando con la sociedad a través de la conexión de los individuos, en las redes sociales, que transmiten estas imágenes vía internet, conectando la acción, sus convicciones y sus vivencias individuales, que son o pueden ser reforzados por los posicionamientos de los sectores políticos y privados.

\section{Referencias bibliográficas}

Barrucho, L (2020). Brasil: O novo epicentro da pandemia de coronavirus?, BBC News Brasil, Londres 20 mai. 2020. https://www.bbc.com/portuguese/brasil-52732620.

Dell'Aglio, D., Almeida, A., \& Stenzel, L. (2013). Construção do Ativismo Político: militantes dos movimentos LGBTTT. Diálogo, 22, 93-106. http://dx.doi.org/10.18316/911.

Hora, D. (2019). Paradoxos do ativismo pós-digital em arte, design e arquitectura. DAT Journal, 4(2), 22-31.

Machado, J. A. S. (2007). Ativismo em rede e conexões identitárias: Novas perspectivas para os movimentos sociais. Sociologias, 18, 248-285.

Mesquita, A.(2008). Insurgências Poéticas : Arte Ativista e Ação Coletiva (1999-2000). Dissertação (Mestrado em História Social) - Faculdade de Filosofia, Letras e Ciências Humanas, universidade de São Paulo.

Sevcenko, N. (2001). A corrida para o século XXI. No loop da montanha-russa. São Paulo: Cia das Letras.

Trindade, R. (2011). O Mito da Multidão: Uma Breve Histórida da Parada Gay de São Paulo. Revista Gênero, Niterói, 11(2), 73-97. 